\title{
Poesia e matéria em Obra Breve, de Fiama Hasse Pais Brandão
}

Wagner Moreira

CEFET-MG

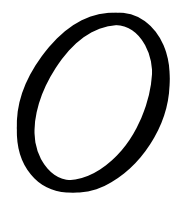

livro Obra Breve, de Fiama Hasse Pais Brandão, apresenta a reunião da produção poética realizada pela própria autora. Ela efetiva, como uma de suas marcas singulares, o fato de se deixar transpassar pela linha de força que pode ser descrita como o princípio informe, indefinido e indeterminado, subjacente e comum a todos os objetos, que adquire alguma forma poética em decorrência de sua natureza e da ação expressiva da escrita. Em outras palavras, a obra de Fiama Brandão dialoga intimamente com aspectos filosóficos que tangenciam tanto o platonismo quanto o aristotelismo, no que diz respeito ao entendimento do que venha a ser a matéria e sua expressão literária.

Para especificar essa manifestação literária, tem-se a intenção de se apontar a tradição visitada de maneira singular, o mapa instituído pelo percurso criativo e o estabelecimento do poético tal qual um espaço limiar como as marcas verificáveis na poesia de Brandão.

Segundo Marcia Arruda Franco, "Fiama compara o seu ensaísmo com a sua poesia, vendo em ambos um pressuposto comum a todo e qualquer produto textual: ser fruto de uma elaboração intencional do escritor". ${ }^{1}$ Para além da intencionalidade da escrita, Franco vê na poeta o desejo de

${ }^{1}$ FRANCO, 2005, p. 43. 
"recolher a mensagem e a materialidade" 2 dos textos sobre os quais se debruça para investigar. Esse olhar perscrutador do passado expõe o fazer literário ao juízo histórico, dizendo uma tradição que ora deve ser deslocada, ora iluminada, ora firmada, quando não está jogando com a simultaneidade desses movimentos.

É a própria Brandão que fala em "Linhas das cartas de Camões" 3 sobre "o emergir dos textos na História literária" como uma solicitação ao leitor para que ele vá ao encontro do que se perdeu. Isto firma a faculdade avaliativa como operador de leitura e de escrita, seja esta acadêmica ou poética. Nesse sentido, vale citar o destaque que Fiama dá em "Um breve livro" (2007, p. 152) para as rimas camonianas:

No primeiro soneto da edição de 1595 das Rythmas de Luís de Camões, lê-se: "um breve livro". Terei, pois, de procurar, apaixonada e talvez infindavelmente, o breve livro que está ali, no todo ou em parte, coeso ou dilacerado por outros poemas (sonetos, canções?). ${ }^{4}$

Nota-se o diálogo direto com a escolha do nome para a sua poesia reunida, Obra Breve, sem espaço para dúvida. Fiama adere o seu fazer poético ao fazer lírico camoniano, tornado parte de sua matéria criativa. Contudo, sua perspectiva é a da segunda metade do século vinte e início do vinte e um. Uma condição garantida pelo lugar histórico no qual se cria, se lê, se vive e se constitui a experiência crítico-artística. Ainda em tempo, deve se ressaltar o afeto orientador de sua busca por um diálogo estreito com o universo poético posto por Camões, além de seu entendimento de brevidade e da formação do

2 FRANCO, 2005, p. 45.

${ }^{3}$ BRANDÃO, 2007, p. 92.

${ }^{4}$ BRANDÃO, 2007, p. 157. 
livro, ambos atualizados pela poeta portuguesa. Lembre-se que Fiama organizou pessoalmente a reunião de seus textos poéticos. Mais uma vez é Brandão que afirma ser sua ação uma "procura órfica" 5 e, como inferência sobre o trabalho de Camões, mas que serve bem para a sua Obra breve, diz: "Livro que, perante a dimensão do heterogêneo é, por definição, breve". ${ }^{6}$

No poema "Nunca manhã suave", de Homanagemàliteratura, de 1976, o título ecoa no início do primeiro verso e confirma o estreito diálogo com a obra camoniana. Refiro-me à Ode $\mathrm{V}$, das obras completas:

\section{ODE V.}

Nunca manhãa suave

Estendendo seus raios por o mundo,

Despois de noite grave,

Tempestuosa, negra, em mar profundo

Alegrou tanto nao, que ja no fundo

Se vio em mares grossos,

Como a luz clara a mi dos olhos vossos.

Aquella formosura,

Que só no virar delles resplandece;

E com que a sombra escura

Clara se faz, e o campo reverdece;

Quando o meu pensamento se entristece,

Ella e sua viveza

Me desfazem a nuvem da tristeza.

O meu peito, onde estais,

He para tanto bem pequeno vaso;

Quando acaso virais

Os olhos, que de mi não fazem caso,

Todo, gentil Senhora, então me abraso

${ }^{5}$ BRANDÃO, 2007, p. 157.

${ }^{6}$ BRANDÃO, 2007, p. 157. 
Na luz que me consume,

Bem como a borboleta faz no lume.

Se mil almas tivera

Que a tão formosos olhos entregára,

Todas quantas pudera

Por as pestanas delles pendurára;

E, enlevadas na vista pura e clara,

(Postoque disso indinas)

Se andárão sempre vendo nas meninas.

E vós, que descuidada

Agora vivereis de taes querellas,

D'almas minhas cercada,

Não pudesseis tirar os olhos dellas;

Não póde ser que, vendo a vossa entr'ellas

A dor que lhe mostrassem,

Tantas huma alma só não abrandassem.

Mas, pois o peito ardente

Huma só póde ter, formosa Dama,

Basta que esta somente,

Como se fossem mil e mil, vos ama,

Para que a dor de sua ardente flama

Comvosco tanto possa,

Que não queirais ver cinza hum'alma vossa. ${ }^{7}$

O texto camoniano abre-se com a comparação entre a satisfação de se sair de uma tormenta marítima e a provocada pelo olhar luminoso do ser amado que supera a primeira em intensidade. Por outro lado, verifica-se no poema de Brandão o movimento do ir-se ao encontro do original, ao se apropriar da expressão inicial daquele, e marcar uma diferença ao deslocar a temática, os elementos e as relações entre ambos. Nesse sentido, pode-se afirmar sobre a visada dada pelo poema contemporâneo que ela se faz pelo transbordamento do olhar e não por um direto reflexo. É assim que se verifica a

${ }^{7}$ CAMÕES, 1843, p. 253-254. 
presença de um despertar de uma "imagem germinada" da linguagem onírica, que corrobora o exercício espiralado histórico, no qual o mesmo nunca é igual a si, por mais semelhante que possa parecer.

A formação dessa imagem não se deixou perturbar pelo corpo noturno e, em verdade, caracteriza-se pela qualidade inerente ao limiar: "nexo entre as cabeças unidas situadas na luz", ou a ligação sutil dada pelos versos sob a iluminação de um processo de releitura. O poema traz à tona o rito da transformação do objeto amado - a "Ode V" camoniana - em uma passagem aberta entre o passado desejado e o presente possível de se instituir. Há nesse mover-se entre a noite e o dia uma oscilação ascendente que permeia essa imagem, anunciando uma imprecisão inata a ela, grau de obscuridade que faz permanecer nuances do noturno na irradiação solar. Esse é o caráter de exceção anunciado pelo título sobre a singularidade do fenômeno imagem, matéria de sua poesia. E também a marca de uma voz que se constitui única, apesar de se apropriar de imagens, versos e expressões de outras vozes autorais.

Veja-se o poema de Homenagemàliteratura:

\section{Nunca manhã suave}

Nunca manhã suave me havia interrompido noites com hipérboles em que ao abrigo do sonho germinara uma imagem. Mas os vultos linhas de tracção para a terra estado sólido adquirido pela flutuação demonstravam um termo. As cores oníricas matizavam o nascente que não se espelha no olhar mas transborda.

Podia a força da madrugada perturbar os impulsos. O orvalho embebera a medula e assim o pólo das imagens se aglutinou.

Mesmo que este bafo exausto sufocasse o corpo nocturno a sintonia no limiar do nascente é expressa com os versos 
sobre o nexo entre as cabeças unidas situadas na luz.

O alvor matinal confuso entre a atenção ao sonho e a distracção. A espiral cintilante do conjunto das frases que oscilam sob o poder da noite e se levantam pela seta do sol. ${ }^{8}$

O livro - plaquete? pois se compõe de três poemas Matéria, na reunião de sua poesia, vem datado de 1960 a 1965, o que o coloca como o primeiro objeto poético a instigar esse fazer de Brandão. Digo isso porque ele se apresenta como o segundo publicado na Obra breve, precedido por Morfismos, de 1961. Desse modo, pode-se inferir a centralidade e complexidade do motivo matéria em sua escrita, pois ele antecede a sua primeira publicação em livro. Corroborando essa constatação, verificase que o primeiro poema daquele livro chama-se "A matéria", uma décima trabalhada em dísticos, pondo em evidência uma variação sobre o modo de veicular esta forma poética feita por Camões. Para além de sua forma, o poema dá a ver uma circunstância de aprendizagem na qual a própria criação se faz corpo delineado, ao mesmo tempo que revela a face secreta de tal aparecimento. Aqui, deve-se ressaltar mais uma ligação entre o interesse poético e o investigativo, pois ao estudar a produção camoniana a autora afirma a necessidade de se pesquisar o seu lado simbólico, exegético. Por outra via, há na aprendizagem da matéria uma cifra que deve aparecer para aquele que interage com ela.

Esse aparecimento pode ser relacionado com o princípio informe, indefinido e indeterminado, subjacente e comum a todos os objetos, que adquire alguma forma universal em decorrência de sua natureza, ou seja, pode ser relacionado à definição mais larga do fenômeno material. Assim, pode-se atribuir àquele o caráter mensurável e conflituoso uma vez que

${ }^{8}$ BRANDÃO, 2007, p. 221. 
reúne em si o limite e o ilimitado, condição mesma da lei e da situação de certo imaginário que constitui o objeto-imagem.

Observe-se o poema:

\section{A matéria}

Aprendo a temperatura o seu frio $o$ ar que tem por dentro a sua arte

Aprendo o sangue o seu calor o fundo

a linha necessária e o sigilo

O que mostra é o tacto em si incide na sua inércia inclui a própria forma

Resume em si o tamanho e o conflito das partes no limite ilimitadas

Ensina a sua lei e a situação o imaginário mostra no objecto 9

"A mão", segundo poema do livro supracitado, também uma décima, exibe uma constituição anafórica que lhe garante um ritmo acentuado, além de subordinar os dísticos ao título, coordenando-os entre si. Isso confirma uma equivalência entre os versos do que se pode depreender certo equilíbrio semânticoformal na expressão do poema. Sua condição sensorial está evidenciada pelo ato de se colocar como gravação ou traço/ escritura que se dá conjuntamente com uma perspectiva de mundo, como se pode ver em "É mão e inscreve / a sua visão".${ }^{10}$ Sua potência pode ser percebida pela imagem vegetal que guarda em si uma tradição como condição inata, "É fruto e nutre / só um futuro". ${ }^{11}$ Assim como o ato de se desdobrar está

\footnotetext{
${ }^{9}$ BRANDÃO, 2007, p. 25.

${ }^{10}$ BRANDÃO, 2007, p. 25.

${ }^{11}$ BRANDÃO, 2007, p. 25.
} 
exposto como mais uma marca desse poético em "É mar e dilata / tudo onde está". ${ }^{12}$ Ao mesmo tempo, "É solo e responde / como um só corpo"13 apresenta tanto o estado concreto por meio de sua imagem que tende para a solidificação quanto para uma fluidez intensa dada por sua conexão com o estado musical; além de trazer à baila a possibilidade do lúdico através da alusão ao jogo carteado. Esse poema estabiliza-se como a experiência humana ao agregar o sensorial e o pensamento no poético.

O poema "Onda", último da série de Matéria, começa e termina por apresentar o desejo do sujeito - igualar-se à medida da "onda": "Pois as coisas cedem e eu me peço / ao tamanho da onda por medida" e "Pois a vejo a ela e a ela cedo / no movimento peço esse tamanho". ${ }^{14}$ Para além do mensurável há um processo de identificação entre as coisas e o sujeito. $\mathrm{Na}$ primeira estrofe, as coisas cedem; na última, o sujeito cede. Esse ato de sofrer um deslocamento ou de abrandar a própria intensidade se associa de imediato à transformação daqueles que se movem como as ondas, oscilação sinuosa e repetitiva que revela um padrão singular de acordo com as forças envolvidas.

Nesse caso, pode-se verificar dois estados que se alternam, a ordem, como uma face racional, legislativa; e o sentimento, como a paixão, o caos, a desordem, "Também assim a ordem e o sentimento / designam a figura de uma onda" ${ }^{15}$ Ainda no terceiro dístico, o termo "figura" acrescenta o caráter da impressão visual, da aparência, da imagem que se constitui como vaga. Esta tem como consequência o amor que cresce

${ }^{12}$ BRANDÃO, 2007, p. 25.
${ }^{13}$ BRANDÃO, 2007, p. 25.
${ }^{14}$ BRANDÃO, 2007, p. 26.
${ }^{15}$ BRANDÃO, 2007, p. 26. 
infinitamente através das palavras - dos poemas? - sugerindo a existência de uma força inominada que motiva tais movimentos, "Pois a causa de amor é a maior / figura que se aumenta por palavras". ${ }^{16}$ Esta perturbação periódica que se propaga num meio material ou no espaço delimita uma prática que se fecha sobre si mesma e abre-se para um desvio de seu próprio sistema de ação, apontando para um exceder o limite que projeta como potência de vontade: "E pois a onda encurva enche solta / no exercício em si fechando a orla / / Liberta se exorbita construída / no vidro cai na sua queda". ${ }^{17}$ Aqui se afirma o desejo do sujeito de ultrapassar a si por meio do exercício de existir como aquele que se transforma, juntamente com o objeto amado. A forma-imagem associa em si aquele que é o amador e aquele que é o amado, transformando-os em algo movente, força em fuga na direção da escritura poética.

Último livro da publicação supracitada, A matéria simples, de 2000, abre-se com uma epígrafe dos sonetos de Camões: "E o vivo e puro amor de que sou feito / Como a matéria simples busca a forma". A força em fuga que transfigura pelo amor - a matéria poética camoniana? - atravessa todo o livro para se consolidar em suas derradeiras páginas.

O primeiro poema, homônimo do livro, traz novamente a questão da linguagem onírica como aquela iluminação obscura que proporciona o trânsito pelo espaço abstrato do devaneio, da fantasia, do pensamento ou da imagem: "Os brilhos que na noite vêm / são dos olhos dos que sonham, / viagens pelos mares de outras águas" ${ }^{18}$ Essa mesma irradiação aponta para a diferença entre a vastidão de uma história canônica e se deleita com uma busca intensa e inerte sobre a

\footnotetext{
${ }^{16}$ BRANDÃO, 2007, p. 26.

${ }^{17}$ BRANDÃO, 2007, p. 26.

18 BRANDÃO, 2007, p. 737.
} 
minúcia do cotidiano, do sujeito, da simplicidade: "São os que não gostam de se elevarem / no ar sobre os antigos oceanos / e amam os pequenos riachos / e o fundo invisível dos poços" ${ }^{19}$

Talvez se possa associar esse desejo com a preferência pelas Rimas em oposição à escolha de senso comum por Os Lusíadas, na obra camoniana. Em outras palavras, a escolha pela produção do livro breve interessa mais, por esse viés, do que aquela feita junto ao texto consagrado exatamente pela relevância do aspecto particular, dado presente nas Rimas, e que se opõem aos faustos históricos do texto épico. Todavia, a água, como elemento fluido, está presente no poema assim como no texto seguinte, "Maré":

\section{Maré}

Quando a maré baixa sob o céu róseo, são a terra e a areia que absorvem o infinito fumo e a neblina.

Além, um pescador; além, uma gaivota; são os mesmos corpos movendo-se, são a mesma inércia da morte.

O pescador revolve a areia acocorado sobre algas douradas em busca de mínimos seres vivos. Um imenso bando de gaivotas intenta separar de súbito o céu da terra como se estas águas da ria, tão lisas, fossem a antimatéria. ${ }^{20}$

A retirada do mar traz à tona a cena descrita na primeira estrofe que afirma a noção do limiar através da praia, lugar

${ }^{19}$ BRANDÃO, 2007, p. 737.
${ }^{20}$ BRANDÃO, 2007, p. 737. 
transitório entre as águas marinhas e a terra, com a caracterização do ilimitado obscuro que gera certo grau de indeterminação para as formas. Todavia, o ato perceptivo da visão apresenta duas figuras ao longe, o pescador e a gaivota. Ambos parecem se beneficiar com o breve momento no qual os "mínimos seres vivos" estão expostos para serem predados. Há uma equivalência entre o homem e a ave que habita esse cenário de breve duração, o espaço que permite o convívio de seres marinhos, terrestres e aqueles que alçam voo pelo ar.

A ação repentina do bando de aves atravessa a imagem descrita como a anunciar um acorde transversal em contato com a melodia da representação. Esse grau de complexidade na ação personificada do grupo de aves - elas intentam, planejam, empreendem - confirma a importância do singular momento por meio da simplicidade da expressão material. Em verdade, esse movimento descobre certa natureza que é o objeto do poema para destacar a força do instante. Essa exatidão temporal, surpreendida pelo ato perceptivo, sensorial, opõe a ria ao mar ou o espaço finito e transitório àquele infinito e perene. A poesia se faz por meio do contraste e estabelece uma tensão como forma de se apreender o objeto de desejo, a fugaz e singela circunstância à beira mar.

Assim, pode-se verificar a instituição do poético como o espaço limiar que transita entre aspectos apresentados da realidade, como os elementos da natureza, e a condição humana seja como o vivente que compõe a cena do existir com um ofício artesanal - o pescador - seja aquele que elabora o ato artístico com a palavra lírica - Camões. Todos esses elementos evidenciam a constante presente nos textos de Brandão, a saber, o diálogo desconcertante com a tradição literária portuguesa. 


\section{Referências bibliográficas}

BENJAMIN, Walter. Passagens. Belo Horizonte: UFMG, 2006.

BRANDÃO, Fiama Hasse Pais. Obra breve. Poesia reunida. Lisboa: Assírio \& Alvim, 2006.

BRANDÃO, Fiama Hasse Pais.O labirinto camoniano e outros labirintos. Lisboa: Teorema, 2007.

CAMÕES, Luis de. Obras Completas. Paris: Officina Typographica de Fain e Thunot,1843.

FRANCO, Marcia Arruda. Fiama camonista. Revista Metamorfoses, Cátedra Jorge de Sena, Rio de Janeiro, n. 6, p. 43 - 54, 2005.

\section{Resumo}

O livro Obra Breve, de Fiama Hasse Pais Brandão, apresenta a reunião da produção poética realizada pela própria autora. Ela efetiva, como uma de suas marcas singulares, o fato de se deixar transpassar pela linha de força que pode ser descrita como o princípio informe, indefinido e indeterminado, subjacente e comum a todos os objetos, que adquire alguma forma poética em decorrência de sua natureza e da ação expressiva da escrita. Em outras palavras, a obra de Fiama Brandão dialoga intimamente com aspectos filosóficos que tangenciam tanto o platonismo quanto o aristotelismo, no que diz respeito ao entendimento do que venha a ser a matéria e sua expressão literária. Este estudo tem por finalidade apresentar e discutir a face dialógica estabelecida entre filosofia e poesia a partir dos textos de Obra Breve, particularmente, dos livros Matéria (19601965), Homenagemàliteratura (1976) e A matéria simples (2006). 


\section{Résumé}

Obra Breve, livre d'Fiama Hasse Pais Brandão, presente une réunion de sa production poétique. Ses poèmes sont, de façon singuilière, croisés par une ligne de force indéfinie, indéterminée, sous-jacente et commune à tous les objets qui y sont transformés en matière poétique par sa propre nature et par l'action expressive de l'écriture. En d'autres termes, l'oeuvre de Fiama Brandão dialogue de façon intime avec les reflexions philosophiques à la fois platonique et l'aristotélique, en ce qui concerne la compréhension de la matière et son expression littéraire. Cet étude vise à présenter et discuter le dialogisme établi entre la philosophie et la poésie en Obra Breve, en particulier dans les livres: Matéria (1960-1965), Homenagemàliteratura (1976) et A Matéria Simples (2006). 